\title{
Design-antropofagia: só me interessa o que não é meu
}

\section{Design-Anthropophagy: I'm Only Interested in What's Not Mine}

\author{
Diseño-antropofagia: \\ sólo me interesa lo que no es mío
}

\author{
Barbara Szaniecki *
}

http://dx.doi.org/10.22409/poiesis. 2033.183-200

\begin{abstract}
RESUMO: Em 1929 era lançada a primeira edição da Revista de Antropofagia afirmando que "a antropofagia não tem orientação ou qualquer forma de pensamento: só tem estômago." A proposta segue de extrema atualidade. Neste artigo serão aproximadas a Antropofagia de Oswald de Andrade e uma arteciência nômade inspirada em Deleuze e Guattari que vem sendo experimentada no Laboratório de Design e Antropologia da Esdi/UERJ. Como o trajeto é longo, faremos três paradas: a primeira para debater os emaranhamentos universidade-sociedade, a segunda para observar a constituição de um design em campo e entre campos na cidade e a terceira para se aproximar de um designdevir com outros. Ao final do percurso pretendemos apresentar algumas armadilhas de um multiculturalismo que se afasta da multiplicidade.
\end{abstract}

PALAVRAS-CHAVE: design; antropofagia; design-anthropology; arte-ciência nômade

\footnotetext{
* Barbara Szaniecki é doutora em Design pela PUC-Rio. É Professora Adjunta da Escola Superior de Desenho Industrial da Universidade do Estado do Rio de Janeiro e Pesquisadora do Laboratório de Design e Antropologia (Esdi/UERJ). E-mail: szanieckibarbara@gmail.com. Orcid: https://orcid.org/0000-0001-5217-4158
} 
ABSTRACT: In 1929, the first edition of the Revista de Antropofagia was published stating that "anthropophagy has no orientation or any form of thinking: it only has a stomach." The proposal is very current. In this article we will approach the Anthropophagy of Oswald de Andrade and a nomadic art-science inspired by Deleuze and Guattari that has been tried in the Laboratory of Design and Anthropology of Esdi / UERJ. As the route is long, we will make three stops: the first to discuss university-society entanglements, the second to observe the constitution of a design in the field and between fields in the city, and the third to approach a design-becoming with others. At the end of the course we intend to present some pitfalls of a multiculturalism that moves away from multiplicity.

KEYWORDS: design; anthropophagy; design-anthropology; art-science nomadic

RESUMEN: En 1929 se lanzó la primera edición de la Revista de Antropofagia afirmando que "la antropofagia no tiene orientación o cualquier forma de pensamiento: sólo tiene estómago." La propuesta sigue de extrema actualidad. En este artículo se aproximarán a la Antropofagia de Oswald de Andrade y una arte-ciencia nómada inspirada en Deleuze y Guattari que viene siendo experimentada en el Laboratorio de Diseño y Antropología de la Esdi / UERJ. Como el trayecto es largo, haremos tres paradas: la primera para debatir los enmarañados universidad-sociedad, la segunda para observar la constitución de un diseño en campo y entre campos en la ciudad y la tercera para aproximarse a un diseñodevenir con otros. Al final del recorrido pretendemos presentar algunas trampas de un multiculturalismo que se aparta de la multiplicidad.

PALABRAS CLAVE: diseño; canibalismo; diseño-antropología; arte-ciencia nómada

Como citar: SZANIECKI, Barbara. Design-antropofagia: só me interessa o que não é meu. Poiésis, Niterói, v. 20, n. 33, p. 183-200, jan./jun. 2019. doi: http://dx.doi.org/10.22409/poiesis.2033.183-200

Poiésis, Niterói, v. 20, n. 33, jan./jun. 2019. 


\section{Design-antropofagia: só me interessa o que não é meu}

\section{Introdução}

Só a antropofagia nos une. Em tempos de polarização generalizada, as palavras de Oswald de Andrade em seu Manifesto Antropófago (1928) ainda soam extremamente atuais. Não é possível trazer em poucas linhas as provocações do movimento antropofágico. Foram inúmeros seus protagonistas, seus conflitos e seus desdobramentos na contemporaneidade. Podemos, contudo, afirmar que não se tratou de mera "aplicação" do hábito antropofágico dos Tupinambás às práticas artísticas e culturais. Segundo Benedito Nunes, o Manifesto da Poesia Pau-Brasil (Correio da Manhã, 1924) procurou conciliar "a cultura nativa e a cultura intelectual renovada, a floresta com a escola". Anos mais tarde, pouco havia sobrado de algum tipo de "conciliação". O Manifesto Antropófago traz uma metafísica bárbara cuja composição é, sempre nos termos de Nunes, 
a metáfora orgânica, inspirada na cerimônia guerreira da imolação pelos tupis do inimigo valente apresado em combate, englobando tudo quanto deveríamos repudiar, assimilar e superar para a conquista de nossa autonomia intelectual; diagnóstico da sociedade brasileira como sociedade traumatizada pela repressão colonizadora que Ihe condicionou o crescimento, e cujo modelo terá sido a repressão da própria antropofagia ritual pelos jesuítas; e terapêutica por meio dessa reação violenta e sistemática contra os mecanismos sociais e políticos, os hábitos intelectuais, as manifestações literárias e artísticas, que, até a primeira década do século XX, fizeram do trauma repressivo, de que a Catequese constituiria a causa exemplar, uma instância sensora, um Superego coletivo. (NUNES, 2001)

Metáfora, diagnóstico, terapêutica. A antropofagia modernista é isso, mas não somente isso. Ela se dá, sobretudo, como devoração. Sua principal formulação - Tupy or not tupy, that's the question - questiona as ontologias essencialistas e, pela referência às práticas tupinambás, valoriza a constituição de si pela relação com o outro, característica das ontologias relacionais do devir. É, contudo, importante ressaltar que esta metafísica bárbara é apenas uma das vertentes do movimento modernista indigenista. Enquanto para esses modernistas, a antropofagia é o caminho para a realização de uma sociedade radicalmente outra, para os Verde-Amarelistas, os índios contribuem para a composição étnica do Brasil, mas suas vidas materiais foram (ou, segundo seus seguidores, ainda devem ser) desmaterializadas e assim formar um espírito nacional. 2019? Não. Foi em 1929 que a primeira edição da revista afirmou que "a antropofagia não tem orientação ou qualquer forma de pensamento: só tem estômago." Haja estômago! Aqui aproximarei a Antropofagia de Oswald de Andrade de uma arte-ciência nômade inspirada em Deleuze e Guattari a partir de experimentos de design realizados na Esdi/UERJ ${ }^{1}$ e, em particular, no Laboratório de Design e Antropologia. Como o trajeto é longo, faremos três paradas: a primeira, para debater os emaranhamentos universidade-sociedade; a segunda, para observar a constituição de um design em campo e entre campos na cidade; e a terceira, para se aproximar de um design-devir com outros.

Poiésis, Niterói, v. 20, n. 33, jan./jun. 2019. 


\section{Emaranhamentos universidade-sociedade: mil platôs e os mil pés da sustentabilidade}

Não sou Esdiana. Embora eu tenha, na minha própria formação, muitos elementos da tradição em design que fizeram a travessia da Europa ao Brasil e aqui constituíram as bases da Escola Superior de Desenho Industrial (Esdi), não me graduei nem me pós-graduei na instituição. Vim de longe e, um dia de 2010, cheguei para um pós-doutorado ao famoso "boulevard" rodeado por casas cinzas e que, em um momento de travessura, adoraria pintar de verde. É nessa qualidade de "estrangeira" - ainda que generosamente acolhida por todos desde o primeiro dia e, desde 2015, para minha felicidade, integrada ao corpo de professores e pesquisadores - que escrevo. Já na minha chegada eram perceptíveis os primeiros sinais de uma crise que, de início, se abateu exclusivamente sobre os funcionários terceirizados, mas que, na sequência, se alastrou e arrastou funcionários, alunos e professores. Uma crise que, com frequência, provocou abatimento e, ao mesmo tempo, pôs a Esdi em movimento. Procurando entender melhor os processos em curso, fui ler a respeito. Encontrei histórias, mitos e lendas dos quais trago aqui algumas linhas.

O decreto de criação da Esdi foi assinado pelo então governador Carlos Lacerda em 1962. Segundo Lucy Niemeyer, "a Escola Superior de Desenho Industrial (ESDI) surgiu como o espaço institucional em que seria produzida a identidade nacional dos produtos."2 (Niemeyer, 1997, p. 88) O projeto institucional apresentava objetivos sociais e econômicos, assim como técnicos e estéticos:

\section{Os criadores do curso viram a escola com possibilidades não só de suprir as necessidades de técnicos em nossa nascente indústria, como também de evitar que fossem pagos "royalties" de patentes importadas e de fazer com que objetos de uso, funcionais e esteticamente aprimoradas, não permanecessem usufruto exclusivo da minoria privilegiada. (NIEMEYER, 1997)}

Encontramos em formulações recorrentes na história da Esdi, a centralidade das ideias de modernidade e de nacionalidade. Ora, essa mesma modernidade que é importada da Europa é efetivamente devolvida na forma de um produto com "identidade nacional". Percebemos assim que não foi apenas nas artes visuais que o modernismo se manifestou, mas também nessa arte-ciência que é o design oriundo da Bauhaus e de Ulm. Talvez seja pos- 
sível pressupor que a Esdi praticou, a seu modo, uma antropofagia, isto é, uma decidida deglutição seguida de devolução, ainda que moderada pela necessidade de servir à industrialização como parâmetro de modernização.

Pelas linhas históricas traçadas por Niemeyer percebe-se que a escola foi fruto de um governo lacerdista com objetivos desenvolvimentistas e que, por sua vez, se estruturou por meio de rigorosos organogramas, processos seletivos, grades disciplinares e profissionais renomados. Também não passa desapercebido o fato que a escola, inicialmente ligada à Secretaria de Educação e Cultura da Guanabara, foi integrada em $1975^{3}$ à nascente Universidade do Estado do Rio de Janeiro por meio de decreto. Segundo Niemeyer, mesmo com a sua incorporação à UERJ, "a escola manteve seu isolamento". A autora apresenta sua percepção de uma "endogenia" esdiana:

(Carmen) Portinho e a maioria dos professores de projeto viam a escola como uma instituição com características peculiares que poderiam se perder caso a unidade se integrasse à estrutura da universidade. Segundo esse grupo, a autonomia da escola devia ser mantida a qualquer preço - mesmo que o preço fosseo isolamento. (Niemeyer, 1997, p. 110)

Que "características peculiares" são essas? Niemeyer problematiza a centralidade da disciplina "desenvolvimento de projeto" com foco na prática, assim como a baixa produção científica dos professores por conta do próprio perfil que seria mais profissional do que acadêmico. A questão me interpela, mas gostaria de abordá-la em outros termos.

Em Mil Platôs, Gilles Deleuze e Felix Guattari apresentam aquelas que seriam as características de uma ciência menor ou nômade. A inspiração vem do "Oriente", mas também do "Sul", em particular das sociedades tidas como primitivas e que se constituem sem Estado. Com base em Pierre Clastres, os autores afirmam que se trata mais do que mera ausência de Estado: essas sociedades conjuram e previnem esse monstro. (DELEUZE; GUATTARI, 1997, v. 5, p. 19) E, na sequência, mencionam os "modelos" que servem de inspiração à ciência nômade: o modelo hidráulico (fluxos mais do que dos sólidos); o modelo problemático (problematizações mais do que afirmações de verdades), o modelo es-

Poiésis, Niterói, v. 20, n. 33, jan./jun. 2019. 
pacial (ocupação mais do que de medição do espaço) e o modelo de devir (trocas de perspectivas mais do que essências). Em que medida essas considerações seriam úteis para apreender as "características peculiares" da Esdi de ontem e de hoje? É improvável que a possibilidade de uma arte-ciência nômade em contraste com uma arte-ciência de Estado estivesse entre as referências teóricas que levaram alguns professores a manter certo distanciamento da UERJ naquele momento, mas me servem hoje de inspiração para certos experimentos com design.

Foi a percepção e a preocupação com a precariedade da universidade pública que me levaram a uma primeira experiência com o Sebrae ${ }^{4}$ a partir de uma demanda à Esdi de intervenção com design no seio do Programa de Desenvolvimento do Empreendedorismo em Comunidades Pacificadas, no auge das Unidades de Polícia Pacificadora do Governo do Estado do Rio de Janeiro ${ }^{5}$. Na ocasião, apesar das ambiguidades do projeto de "pacificação", levei uma turma inteira da graduação para realizar cartografias e desenvolver projetos de design com várias iniciativas no Morro dos Prazeres, situado perto da Esdi. No final do período, disponibilizamos os materiais aos parceiros e moradores, mas nos defrontamos também, com muito pesar, com a descontinuidade da proposta.

No ano de 2015, Zoy Anastassakis, parceira-parenta em muitas ações e reflexões, articulou uma cooperação internacional entre o recém-criado Lada/Esdi/UERJ (Laboratório de Design e Antropologia) ${ }^{6}$ e o Code/KADK (Codesign Research Center, Royal Danish Academy of Fine Arts, School of Design). Com base nos experimentos de codesign que o Code/KADK vinha desenvolvendo na Dinamarca, sugeriu que articulássemos parcerias com bibliotecas públicas. E foi assim que estudantes de graduação da Esdi e de pós-graduação do Lada entraram em contato com a Biblioteca Parque Estadual, com a Biblioteca comunitária da Prainha e com a Biblioteca do Museu de Arte do Rio. Passaram a ir a campo semanalmente com o intuito de observar participativamente o que lá acontecia e projetar colaborativamente outras bibliotecas possíveis. Os processos foram apresentados aos educadores, bibliotecários e gestores no final do período. 
A crise fazia-se sempre mais presente em todo o Estado e levou ao fechamento das Bibliotecas Parque Estadual em 2016 (já abriram e fecharam algumas vezes) e ao adiamento da abertura da UERJ em 2017 por conta da falta de condições de trabalho - atraso no pagamento de salários e bolsas, assim como ausência de limpeza e segurança. A crise do Estado estava em parte relacionada à dependência econômica de uma commodity - o petróleo - cujo preço flutua mundialmente, assim como de parcerias público-privadas cuja gestão não é transparente. Em suma, em pleno século XXI, ficava claro que não havíamos conseguido superar o problema do extrativismo e do patrimonialismo - "confusão", ou melhor, apropriação privada do que é público. Como evitar as repetidas crises das instituições e de equipamentos que dependem do financiamento do Estado? Como ampliar a dimensão "pública" da universidade para além do Estado, isto é, com, mas também contra ele, no sentido clastriano? Como abrir caminho para as sutilezas da sustentabilidade? Algumas possibilidades poderiam passar por um amplo e democrático debate na universidade. Ora, isso tem sido impossível no seio de uma insustentável polarização.

Enquanto não abrimos esse debate, a universidade pública é publicamente acusada de não ser útil à sociedade. A afirmação de que é fundada no tripé "ensino, pesquisa e extensão" parece não ser convincente, talvez por ser a extensão - as atividades abertas à sociedade - frequentemente descartada na medida em que as atividades de ensino, pesquisa e coordenação absorvem as cargas horárias ou porque ela não é, por conta das múltiplas formas que assume, suficientemente percebida como tal. No caso do Sebrae, a atividade envolveu a graduação, a pós-graduação e, de certo modo, se caracterizou como extensionista, na medida em que se envolveu totalmente com os parceiros da comunidade. Também no caso das bibliotecas públicas, a atividade promoveu articulações internas à Esdi entre graduação e pós-graduação, além de articulações externas com as bibliotecas - constituídas elas próprias por gestores, funcionários e público -, assim como com a instituição internacional. O tripé é, na realidade, um mil pés. A universidade não é apenas os estudantes, os professores e os funcionários que a constituem institucionalmente; ela é todos aqueles com quem se emaranha todos os dias. Não existe um "dentro" que é uni-

Poiésis, Niterói, v. 20, n. 33, jan./jun. 2019. 
versidade e um "fora" que é sociedade. Mais do que ser defendida frente à sociedade, a universidade pública deve ser vivida: devorar e ser devorada todos os dias.

Em Mundobraz, Giuseppe Cocco traz algumas reflexões sobre o Brasil no cenário mundial contemporâneo. Critica, por exemplo, autores que veem na precarização da moradia e na flexibilização do trabalho a nível global algo como uma "brasilianização" do mundo. A essa "brasilianização", a qual é atribuída conotação fortemente negativa, ele contrapõe um devir-Brasil do mundo e um devir-mundo do Brasil: uma contínua troca de perspectivas prenhe de possíveis. Talvez a UERJ, com sua política de cotas, seja a realização mais potente de uma universidade que comeu e regurgitou mundos inteiros de conhecimentos. Nessa deglutição e devolução, nesses muitos devires, fez-se universidade pluriversal (ESCOBAR, 2018) e talvez, justamente por sua pluriversidade, é continuamente atacada.

\section{Arte-ciência nômade: design em campo e entre campos na cidade}

Muitos dos experimentos acima mencionados não teriam sido possíveis em outro lugar que não fosse a Esdi. Aqui me refiro não apenas à instituição, mas sobretudo à sua localização. A unidade se situa entre o Passeio Público e a rua Evaristo da Veiga, entre os Arcos da Lapa e a Praça da Cinelândia. De repente, fez sentido para mim a vontade dos professores de permanecer ali ao invés de se deslocar para o campus Maracanã. Assim como passou a fazer sentido pensar que, ali, uma arte-ciência nômade poderia encontrar solo fértil para crescer.

Como disse anteriormente, em Mil Platôs Deleuze e Guattari fazem uma distinção entre ciência nômade e ciência de Estado e, para isso, distinguem espaço liso e estriado. Tomam como exemplo a diferença entre o tecido e o feltro. No caso do tecido, sua constituição se dá pelo cruzamento perpendicular de dois tipos de linhas paralelas - as verticais e as horizontais - que geram, por sua vez, um espaço delimitado. Com efeito, o tecido pode ser infinito em comprimento, mas não na sua largura, pois essa será restrita pelo quadro da urdidura. Tecido, tal espaço também apresenta necessariamente um avesso e um di-

Poiésis, Niterói, v. 20, n. 33, jan./jun. 2019. 
reito, configurando assim a imposição de um limite e de uma moral. Os autores se perguntam então "se não foi em função de todas essas características que Platão pôde tomar o modelo da tecelagem como paradigma da ciência "régia", isto é, da arte de governar os homens ou de exercer o aparelho de Estado?" (Deleuze; Guattari, 1997, v. 5, p. 181) Já o feltro, ele não é tecido e sim emaranhado. Aproveito então para perguntar se essas reflexões não se aplicariam às cidades.

Não é por acaso que, para Deleuze e Guattari, o mar é o arquétipo do espaço liso, enquanto a cidade é o arquétipo do espaço estriado. Com os arquétipos, fica mais claro que não se trata apenas de dizer o que cada espaço "é" como, sobretudo, de observar as possibilidades que se abrem quando ele é percorrido. O liso e o estriado se distinguem, por exemplo, pela relação inversa entre o ponto e a linha: no estriado, a linha se constitui pelo espaço entre dois pontos, enquanto no liso, é o ponto que é definido no percorrer a linha. Contudo, a simples oposição "liso-estriado" remete, na realidade, a misturas, sobreposições e também reversões que ocorrem por meio de um complexo jogo de movimentos dissimétricos. Por ora, concluem os autores, "seria preciso dizer simplesmente que existem dois tipos de viagem, que se distinguem segundo o papel respectivo do ponto, da linha e do espaço". (Deleuze; Guattari, 1997, p. 189)

Os autores trazem em sua bagagem alguns exemplos literários. Na minha, trago os diferentes modos de "viajar" na cidade. Penso na diferença entre o percurso do trabalhador que sai de casa e vai à fábrica ou escritório e aquele do ambulante que efetua suas paradas em função dos fregueses. Penso na diferença entre o pesquisador de Estado que sai do laboratório para ir a campo e o pesquisador nômade que sai pelas ruas à procura de parceiros, à caça de conversas e à cata de questões. Dois tipos de viagem. Dois tipos de design em campo e entre campos.

Poiésis, Niterói, v. 20, n. 33, jan./jun. 2019. 


\section{Design Anthropology e antropofagia}

Desde 2013, essa experimentação de uma arte-ciência nômade foi em parte possibilitada pelo encontro entre design e antropologia. Indicado por Zoy, o livro Design Anthropology - Theory and Practice, organizado por Wendy Gunn, Ton Otto e Rachel Charlotte Smith e publicado em 2013, me trouxe uma primeira percepção sobre o "encontro" entre design e antropologia denominado Design Anthropology. Antes de abordá-lo, os organizadores apresentam o que consideram as principais características das duas disciplinas.

O design é tido como uma atividade de concepção e planejamento capaz de dar forma, estrutura e função a uma ideia, antes de realizá-la no mundo. Também é salientado que, pelo fato de constituírem uma força de trabalho especialista, os designers acabam constituindo um domínio de atividade separado. Já a antropologia consiste no estudo comparado de sociedades e culturas, em particular aquelas não-ocidentais. Baseados em pesquisas empíricas detalhadas - a etnografia e, em particular, a observação participante, esse estudo exige a imersão de longo prazo de um pesquisador em contextos sociais concretos. E o encontro entre design e antropologia, como seria?

Não é de hoje que os designers compreenderam que as metodologias etnográficas seriam úteis para o desenvolvimento de produtos e sistemas. Com efeito, a observação em campo e sua transformação em dados pode contribuir para uma melhor compreensão da experiência do usuário e, consequentemente, servir ao aprimoramento do produto. Mas, alertam, a proposta de design anthropology não pode ser reduzida à utilidade da pesquisa etnográfica e da informação para o projeto de design.

Embrenhando-se por outras pistas, afirmam por exemplo que a antropologia é voltada para a observação e documentação e, de certo modo, fica em um eixo entre passado e presente, enquanto o design é voltado para o projeto e intervenção na vida cotidiana das pessoas e, assim, se situa em um eixo entre presente e futuro. Na percepção dos autores, dificilmente um antropólogo se põe na perspectiva de impactar as populações que estuda e ainda menos de lhe projetar futuros. E, recíproca mas não simetricamente, um designer dificilmente se põe na perspectiva de estudar as populações que seus projetos impactam 
e ainda menos de compreender seu passado. Concluem que "a tarefa do design anthropology é integrar e desenvolver as qualidades tradicionais (das duas disciplinas) em novos modos de pesquisa e colaboração, trabalhando em direção à transformação sem sacrificar a empatia e a profundidade de compreensão". (GUNN; OTTO; SMITH, 2013)

Seguindo a mesma linha, Anastassakis e Kuschnir afirmam que, quando se fala em Design Anthropology, o que está em jogo "não é nem uma antropologia do design, nem um design antropológico, mas, sim, o exercício de uma experimentação interdisciplinar que busca operar a partir da conjugação entre as duas disciplinas". (ANASTASSAKIS; KUSCHNIR, 2014, p. 5) Para apreender a potência dessa relação interdisciplinar, foram realizados, ainda em 2013, alguns encontros entre alunos da Esdi/UERJ e alunos do Ifcs/UFRJ. Muito sinteticamente: por um lado, os alunos de design se viram no papel de "fazedores" desejando a capacidade analítica dos alunos de antropologia e, por outro, os alunos de antropologia se viram no papel de "analisadores" desejando a capacidade fazedora dos alunos de design. A fome era grande. Empatia e compreensão é o que designers e antropólogos devem levar à campo, mas é possível afirmar que o encontro que leva à criação do design anthropology é... antropófago!

"Perguntei a um homem o que era o Direito. Ele me respondeu que era a garantia do exercício da possibilidade. Esse homem chamava-se Galli Mathias. Comi-o", escrevia Oswald em seu Manifesto Antropófago. Perguntei a um homem o que era o Design. Ele me respondeu que era conceber uma ideia e planejá-la, dar forma, estrutura e função a essa ideia antes de realizá-la no mundo e de modo a delimitar um campo. Esse homem chamava-se Galli Mathias. Comi-o. Comentei que a Esdi, em seus primeiros anos, parece ter sido atravessada por algo como um desejo de arte-ciência nômade. Embasada nas reflexões de Deleuze e Guattari acerca das complexas relações espaciais entre liso e estriado, considerei que sua localização no centro da cidade funciona como um convite para a prática de um design em campo. Alguns experimentos iniciais nos aproximaram das práticas etnográficas e, em seguida, de um design anthropology. Alguns experimentos posteriores nos levaram à convicção de que, aqui em Pindorama, o design anthropology não acontece tal como um encontro de homens cordiais e sim mais se assemelha a um ato antropófa-

Poiésis, Niterói, v. 20, n. 33, jan./jun. 2019. 
go. Um design em campo e no encontro com outros campos foi se constituindo no atravessamento do feltro urbano carioca com suas ruas, morros, bibliotecas, praças, hortas. Foi se constituindo antropofagicamente no atravessamento de outros campos de conhecimento, não apenas a antropologia, como também a arquitetura e a arte com suas metodologias e experiências: situacionistas, neoconcretistas... multitudinárias. É nesse atravessamento que o próprio campo do design adquire consistência e coesão, e tudo isso com alegria: "a alegria é a prova dos nove". (DE ANDRADE, 1928)

\section{Design com como devir com: "só me interessa o que não é meu"}

Como dizia, o encontro do design com outros campos, assim como os encontros do designer em campo não são necessariamente cordiais, muito pelo contrário, mais se assemeIham a devorações. Faz-se necessário retornar às teorias das relações e, portanto, a alguns dos "modelos" que nutrem as artes-ciências nômades: o hidráulico e o do devir. A ciência régia (ou de Estado), nos dizem Deleuze e Guattari, é inseparável de um modelo hilemórfico (DELEUZE; GUATTARI, 1997, p. 35) isto é, de uma relação estática formamatéria, enquanto a ciência nômade tende a uma relação dinâmica material-forças, ou seja, mais fluída do que sólida.

Dessa distinção, decorre uma outra. Operando por dedução ou indução, as ciências régias tratam "as diferenças de tempo e lugar como outras tantas variáveis das quais a lei extrai precisamente a forma constante". Ou seja, mesmo sob condições diversas e fenômenos variáveis, o que essa ciência procura extrair é a constante que permite reproduzir o modelo. À diferença das ciência de reprodução, as ciências nômades - ambulantes e perambulantes - nunca se preocupam em reproduzir e sim em seguir: "Reproduzir implica a permanência de um ponto de vista fixo, exterior ao reproduzido: ver fluir, estando na margem. Mas seguir é coisa diferente do ideal do reprodução. Não melhor, porém outra coisa. Somos de fato forçados a seguir quando estamos à procura das "singularidades" de uma matéria ou, de preferência, de um material, e não tentando descobrir uma forma". (DELEUZE; GUATTARI, 1997, p. 40) Uma arte-ciência que segue é aquela na qual os pro- 
cessos são tão importantes quanto os projetos que os precedem e os produtos que os sucedem e, sobretudo, aquela que embaralha a linearidade dessas relações. É aquela que, no percurso, permite-se a troca de pontos de vista.

Como pensar e praticar um "design com outros" no sentido de uma abertura radical à alteridade? Indicar a possibilidade de uma arte-ciência nômade a partir da questão do devir nos leva, antes mesmo da antropofagia proposta por Oswald de Andrade como Tupy or not tupy: that's the question, ao canibalismo Tupinambá, tal como analisado por Eduardo Viveiros de Castro. Em A inconstância da alma selvagem, Viveiros de Castro retoma as palavras do padre jesuíta Antonio Vieira para descrever "a gente dessas terras" como "a mais bruta, a mais ingrata, a mais inconstante, a mais avessa, a mais trabalhosa de ensinar de quantas há no mundo". (VIEIRA apud VIVEIROS DE CASTRO, 2002, p. 185). A inconstância da alma selvagem demorou a ser compreendida como expressão de um modo de ser onde "é a troca, não a identidade, o valor fundamental a ser afirmado". (CLIFFORD apud VIVEIROS DE CASTRO, 2002, p. 206) Em outros termos, é a afinidade relacional e não a identidade substancial o valor principal, o que leva Viveiros de Castro a concluir que "essa sociedade não existia fora de uma relação imanente com a alteridade". (VIVEIROS DE CASTRO, 2002, p. 220) E a máxima expressão dessa relação é a incorporação do outro no caso dos Tupinambás.

Ainda segundo Viveiros, a antropofagia canibal dos Tupinambás era preparada por uma antropofagia dialógica. Antes de comer, era preciso conversar com o inimigo e esse diálogo era um elemento essencial e não secundário do rito. A antropofagia é também semiofagia. Faz todo sentido considerar que, no campo do design e, sobretudo, no encontro interdisciplinar denominado design anthropology, a antropofagia se faz semiofagia, ou seja, incorporação do signo do outro. Ora, mesmo o ato semiofágico deve ser precedido de uma conversa. No Lada, já constituído como cozinha-laboratório desde 2013, procuramos debater-devorar essa questão e chegamos à formulação e experimentação de "dispositivos de conversação." (ANASTASSAKIS, SZANIECKI, 2016) Trata-se de protótipos, provótipos ou outras "coisas de design" (BINDER et al., 2011) que possam provocar uma con-

Poiésis, Niterói, v. 20, n. 33, jan./jun. 2019. 
versa. "Roteiros, roteiros, roteiros, roteiros, roteiros, roteiros, roteiros". (DE ANDRADE, 1928).

O termo "dispositivo" é aqui utilizado no sentido foucaultiano, ou seja, para se referir ao emaranhado de elementos discursivos e não discursivos em suas relações de poder como também à sua potência de mudar o jogo. Já o termo "conversação" vem de uma necessária distinção de conversa e é aqui utilizado no sentido bakhtiniano, qual seja, para se referir ao emaranhado de palavras de uns apropriadas por outros. Pelo menos a metade das palavras de qualquer homem que vive em sociedade são palavras de outrem (BAKHTIN, 1984) e, portanto, é por meio dessas palavras emprestadas que formamos opiniões, expressamos indignação ou entramos em acordos para a ação. O que Bakhtin assinala com sua análise dialógica da conversação é o próprio processo de subjetivação como uma constituição "com o outro", recíproca embora não simétrica, através das palavras: da mãe com o filho, do autor com o personagem... E, por que não, do designer com os outros com quem ele se encontra em campo? São "dispositivos de conversação" as "coisas" tangíveis geradoras de palavras, que temos levado às ruas, morros, bibliotecas, praças e hortas. "Só me interessa o que não é meu". (DE ANDRADE, 1928) O design com é um devir com.

\section{Considerações finais}

Embrenhando-nos pela mata chegamos em uma clareira. Até aqui vimos os emaranhamentos universidade-sociedade que formam a base da sustentabilidade. Seguimos com as travessias de muitos campos por parte de uma arte-ciência que, assim, constituiu-se historicamente como design. E percebemos, por último, os devires que se abrem nos processos dialógicos do design com outros. Se muito dessa bagagem reflexiva eu já trazia ao chegar na Esdi, outras tantas reflexões se materializaram ao longo dos experimentos realizados nos últimos anos. 
Por sua vez a Esdi, escola que nasceu por decreto em 1962 e abriu suas portas em 1963, segue sua travessia. Em 2005 abriu curso de mestrado e, em 2013, curso de doutorado. Recentemente, em 2016, os três departamentos existentes ganharam um irmão com a criação do curso de Arquitetura e Urbanismo. É uma ousadia visto que, ao contrário da tradição, desta vez é uma escola de design que incorporou a arquitetura e o urbanismo. No mesmo ano de 2016, foi aprovado o novo currículo para a graduação em design abrindo a antiga grade às novas possibilidades da contemporaneidade. Apesar de tudo isso, a percepção de fragilidade persiste quando não apenas a dimensão pública da educação superior, assim como todo o campo da educação, é violentamente atacado. Aqui, bem no meio da clareira, encontramos uma armadilha semelhante ao verde-amarelismo com o qual se deparou o movimento modernista.

Sempre em Mundobraz, Giuseppe Cocco aborda as reflexões produzidas nos últimos anos sobre a "colonialidade do poder" como uma necessária ruptura com "a dimensão eurocêntrica de um futuro mecanicamente produzido pela linha evolutiva do 'progresso'". (COCCO, 2009, p. 43) As sociedades ocidentais projetam efetivamente para o resto do mundo as suas imagens. Ora, lembra o autor, uma dessas imagens é aquela do multiculturalismo que, embora sedutor, equivale a uma multiplicação de conjuntos homogêneos e isolados - que tal como ilhas de um arquipélago não conversam entre si. A multiplicação de identidades não favorece os devires ou os processos de diferenciação; muito pelo contrário, ela tende a fortalecer o seu governo. Onde a potente antropofagia reduziu-se ao multiculturalismo com sua característica fragmentação? Em que medida o multinaturalismo - uma só cultura com diferentes corpos - a recomporia? Deixo aqui essas provocações junto ao convite de seguir carregando o oriente na travessia do ocidente, sustentando o sul na conversa com o norte por meio de uma arte-ciência nômade do design.

Poiésis, Niterói, v. 20, n. 33, jan./jun. 2019. 


\section{Notas}

${ }^{1}$ Escola Superior de Desenho Industrial da Universidade do Estado do Rio de Janeiro.

${ }^{2}$ Niemeyer frisa a importância do design de produto que deixa à margem a programação visual.

${ }^{3}$ Divergência: no livro consta 1973, no site é mencionado o decreto número 67 de 11 de abril de 1975.

${ }^{4}$ Serviço Brasileiro de Apoio às Micro e Pequenas Empresas

${ }^{5}$ A primeira UPP foi instalada em 2008 no Morro Dona Marta em Botafogo.

${ }^{6}$ Para informações, visitar http://ladaesdi.com.br/.

\section{Referências}

ANASTASSAKIS, Zoy. SZANIECKI, Barbara. Conversation Dispositifs: Towards a Transdisciplinary Design Anthropological Approach. In SMITH et al. (Ed.). Design Anthropological Futures. Londres; Nova York: Bloomsbury Academic, 2016.

ANASTASSAKIS, Zoy; KUSCHINIR, Elisa. Trazendo o design de volta à vida: considerações antropologicamente informadas sobre as implicações sociais do design. In LIMA, Guilherme de Cunha; MEDEIROS, Ligia. Textos selecionados de design 4. 2013.

BAKHTIN, Mikhail. Ésthétique de la création verbale. Paris: Gallimard, 1984.

BINDER, T.; DE MICHELIS, G.: EHN, P.; JACUCCI, G.; LINDE, P.; WAGNER, I. Design Things. Cambridge, MA: MIT Press, 2011.

COCCO, Giuseppe. Mundobraz - O devir-mundo do Brasil e o devir-Brasil do mundo. Rio de Janeiro; São Paulo: Record, 2009.

CLASTRES, Pierre. A sociedade contra o Estado. São Paulo: Cosac \& Naify, 2003.

DELEUZE, Gilles; GUATTARI, Félix. Mil platôs - capitalismo e esquizofrenia (volume 5). São Paulo: editora 34, 1997. 
DE ANDRADE, Oswald. A Utopia Antropofágica. São Paulo: Globo, 2001.

ESCOBAR, Arturo. Designs for the Pluriverse. Radical Interdependence, Autonomy, and the Making of Worlds. Durham; Londres: Duke University Press, 2018.

GUNN, Wendy; OTTO, Ton; SMITH, Rachel Charlotte (Org.). 2013. Design Anthropology: Theory and Practice. Londres; Oxford; Nova York; Nova Deli; Sydney: Bloomsbury Academic, 2013

NEVES MARQUES, Pedro (Org.). The Forest and the School - Where to Sit at the Dinner Table. Berlim: Colônia: Archive Books, Akademie der künste der Welt, 2014.

NIEMEYER, Lucy. Design no Brasil - origens e instalação. Rio de Janeiro: 2AB, 1998.

NUNES, Benedito. A antropofagia ao alcance de todos. Introdução à DE ANDRADE, Oswald. A Utopia Antropofágica. São Paulo: Globo, 2001.

VIVEIROS DE CASTRO, Eduardo. A inconstância da alma selvagem - e outros ensaios de antropologia. São Paulo: Cosac \& Naify, 2002. 